\title{
Abordagem da Leitura e da Gramática na Prova de Língua Portuguesa do Processo de Avaliação Seriada - UEJ
}

APPROACH OF READING AND GRAMMAR IN PORTUGUESE LANGUAGE OF THE SERIAL EVALUATION PROCESS - UEM

Rosilene da Silva de Moraes Cavalcanti* Marilurdes Zanini**

Resumo: Este artigo tem como objetivo discutir as abordagens de leitura e de gramática que permeiam a prova de Língua Portuguesa do Processo de Avaliação Seriada da Universidade Estadual de Maringá - PAS-UEM, um instrumento que permite o ingresso dos candidatos ao ensino superior da Universidade Estadual de Maringá. O interesse, ao final, é observar se as concepções que subsidiam a elaboração das questões se coadunam com aquelas preconizadas pelos Parâmetros Curriculares Nacionais e com as Diretrizes Curriculares Estaduais do Paraná. Nesse percurso, procura também verificar se as questões propostas, no seu grau de dificuldade, estabelecem a ponte entre os níveis de ensino médio e acadêmico, já que o Processo, teoricamente, espera interagir com esses níveis. Para isso, esta pesquisa qualitativa analisa três questões da prova de Língua Portuguesa do PAS-UEM 2011, etapa III, que apresenta cinco questões de múltipla escolha a partir de dois textos de gêneros diferentes. Os resultados demonstram que, ao abordar a

* Mestre em Letras pela Universidade Estadual de Maringá (2013). Professora da Graduação e Pós-Graduação da Faculdade Eficaz - Maringá. Contato: rmcavalcant@ig.com.br.

** Doutora em Letras pela Universidade Estadual Paulista Júlio de Mesquita Filho (1991). Professora no curso de Graduação em Letras e do Programa de Pós-Graduação da Universidade Estadual de Maringá - Maringá. Contato: marilurdes.zanini@hotmail.com. 
leitura e a gramática, o candidato tem de recorrer ao contexto, tomando o texto como espaço de interação entre autor e leitor. As questões referentes aos aspectos gramaticais são abordadas de forma contextualizada, quando a reflexão sobre a língua e a linguagem é marcadamente necessária e orientada. Palavras-chave: PAS-UEM. Leitura. Gramática.

Abstract: This research aims to identify the reading concept of the PAS-UEM Test, an instrument that allows the admission in the Higher Education at the Maringá State University. Specifically, it is intended to verify, to answer the proposed questions, the entrant must use the steps of the interactive reading process: reading, comprehension and interpretation. In order to accomplish it, analyse the Portuguese Language Test of PAS-UEM 2011, phase III that presents five multiple choices questions to be answer based in two texts of different genres. The results shows that more emphasis is given to questions related to grammar aspects, although it relies on the reading in order to be answered, the process of reading, comprehension and interpretation is not executed.

Keywords: PAS-UEM. Reading. Reading assessment.

\section{Considerações Iniciais}

O ensino de Língua Portuguesa como língua materna, no estado do Paraná, ancora-se nos Parâmetros Curriculares Nacionais (PCN) e nas Diretrizes Curriculares Estaduais (DCE), em que o ensino-aprendizagem neste trabalho, o de Língua Portuguesa - procura articular três variáveis:

Aluno - é o sujeito da ação de aprender, aquele que age sobre o objeto do conhecimento.

Língua portuguesa - objeto de conhecimento, tal como se fala e se escreve fora da escola, a língua que se fala nas instâncias públicas e a que existe nos textos escritos que circulam socialmente.

Ensino - enfoque teórico, concebido como a prática educacional que organiza a mediação entre sujeito e objeto de conhecimento. (BRASIL, 1997, p. 25). 
Como orientadores dessa articulação, são propostos eixos organizadores dos conteúdos da disciplina Língua Portuguesa - uso e reflexão, os quais consideram que a língua se realiza no uso, nas práticas sociais, ou seja, no momento em "que os indivíduos se apropriam dos conteúdos, transformando-os em conhecimento próprio, por meio da ação sobre eles" (BRASIL, 1997, p. 35).

Ao tomar o uso e a reflexão como eixos norteadores do ensino, nos documentos oficiais, assume-se uma concepção de língua como um sistema de signos que se põe à disposição dos seus usuários, e são mobilizados na linguagem segundo a motivação provocada pelas diferentes situações de interação verbal. Dessa forma, a língua é um fenômeno social, ou seja, nasce da necessidade de interação (política, social, econômica) entre os homens, enquanto a linguagem é a ação interindividual que se adéqua às necessidades de interação entre os sujeitos desse processo, isto é, a língua é uma prática social, coletiva e a linguagem é

... uma forma de ação interindividual orientada por uma finalidade específica; um processo de interlocução que se realiza nas práticas sociais existentes nos diferentes grupos de uma sociedade, nos distintos momentos da sua história. (BRASIL, 1997, p. 22).

Essa concepção de linguagem traz para a situação de ensino-aprendizagem a compreensão de que o ensino de língua materna deva se pautar e se concretizar em atividades de fala/escuta, de leitura, de escrita e de análise linguística. Nesses princípios teóricos, assenta-se o objetivo de discutir as abordagens de leitura e de gramática que permeiam a prova de Língua Portuguesa do Processo de Avaliação Seriada da Universidade Estadual de Maringá (PAS-UEM), uma modalidade democrática de acesso, que permite o ingresso dos candidatos ao ensino superior da Universidade Estadual de Maringá (UEM). Isso se justifica uma vez que a prova, em princípio, objetiva avaliar a capacidade do candidato de ler textos de diferentes níveis de linguagem; de perceber as relações estruturais do padrão culto (o sistema ortográfico vigente, as relações morfossintáticas e semânticas entre os fatos da língua); de estabelecer relações entre os textos e os contextos a que se referem, bem como reconhecer o emprego de recursos linguísticos utilizados na sua organização. 
Na prova, como se concretizam (ou não) as concepções de língua e de linguagem nas questões que a compõem? é a pergunta que esperamos responder neste artigo. Para respondê-la, o centro da nossa atenção é o processo, em que se alinham os objetivos da prova, a elaboração das questões e a análise crítica dessas questões, tomando os pressupostos contidos nos PCN e nas DCE, expandindo as concepções interacionistas das habilidades de leitura e de análise linguística, e a proposta do PAS-UEM, exposta na página da Comissão do Vestibular Unificado da Universidade Estadual de Maringá - CVU/UEM ${ }^{1}$. Para isso, elegemos a prova elaborada na etapa III, de 2011, última do processo, da qual participaram alunos do ensino médio que concorreram nas duas etapas anteriores, encerrando e classificando, na somatória, os primeiros ingressantes nos diversos cursos de graduação ofertados pela UEM.

\section{Leitura}

Leitura é um processo que trilha quatro níveis: decodificação, compreensão, interpretação e retenção. Nesse processo, o texto torna-se um espaço de encontro entre o autor e o leitor, que, juntos, constroem - ou procuram construir - os seus sentidos, ou seja, trata-se de "um processo no qual o leitor constrói o significado do texto partindo dos seus conhecimentos prévios sobre o assunto, sobre autor, e de tudo o que sabe sobre a língua: características do gênero, do portador, do sistema da escrita etc.”. (BRASIL, 1997, p. 41).

Esse ato dialógico, interlocutivo, envolve demandas sociais, históricas, políticas, econômicas, pedagógicas e ideológicas de determinado momento. Ao ler, o indivíduo busca as suas experiências, os seus conhecimentos prévios, a sua formação familiar, religiosa, cultural, enfim, as várias vozes que o constituem. Nesse conceito, os passos envolvem a visão da linguística estruturalista, que concebe a leitura como decodificação, ou seja, a competência de passar do código escrito para o código oral. Entretanto, entendemos que só decodificar não basta, visto que, ao parar nessa etapa, o leitor restringe o conteúdo do texto a, praticamente, um conteúdo e a leitura

\footnotetext{
${ }^{1}$ Disponível em: <www.pas.uem.br>.
} 
torna-se um ato automatizado, que não favorece maior envolvimento do leitor com o texto. Por isso, defendemos que a leitura extrapole a mera decodificação em busca da compreensão, segundo a qual, o leitor envolve-se com o texto, procurando entendê-lo no seu contexto de produção, com ênfase no espaço ocupado pelo autor. Ao trilhar esse caminho, esperamos um envolvimento maior e uma atitude responsiva do leitor com o texto, quando ele participa da produção dos sentidos, considerando os contextos de produção e de uso, recorrendo ao próprio conhecimento de mundo. Marca-se aí o processo de interação entre o leitor e o texto em que a ênfase está no leitor ativo, capaz de buscar no texto informações, dialogar com ele, estabelecendo relações com o contexto e ativando os seus conhecimentos prévios. Para isso, o leitor, inicialmente, contata o material linguístico disponibilizado pela organização textual, cujas escolhas lexicais permitirão ao leitor construir, de modo descendente, os sentidos do texto. A construção do significado deixa de ser linear e propicia ao leitor envolver-se no processo trazendo sua contribuição, que será tanto maior quanto o seu conhecimento prévio sobre o tema abordado:

A visão da realidade provocada pela presença do texto depende da bagagem de experiências prévias que o leitor traz para a leitura. $\mathrm{O}$ texto não contém a realidade, reflete apenas segmentos da realidade, entremeados de inúmeras lacunas, que o leitor vai preenchendo com o conhecimento prévio que possui do mundo. (LEFFA, 1996, p. 14).

Dessa forma, a leitura, uma atividade interativa altamente complexa de produção de sentidos, se realiza com base nos elementos linguísticos presentes na superfície textual e na sua forma de organização.

A leitura não é, pois, uma atividade meramente mecânica, mas, sim, um processo que se realiza em etapas, tratadas com a mesma importância, já que uma serve de base para a seguinte: 1) decodificação; 2) compreensão; 3) interpretação; 4) retenção.

A decodificação consiste no reconhecimento dos símbolos escritos e de sua ligação com os respectivos significados e pode desenvolver-se em dois níveis: primário e secundário. No nível primário, o leitor limita-se à identificação dos símbolos linguísticos, decodificando as palavras. É o 
primeiro passo para entrar na compreensão, que só ocorrerá no nível secundário, em que o leitor apreende o significado das palavras e expressões, até o momento desconhecidas, a partir do contexto em que estão inseridas (MENEGASSI, 1995). Ao alcançar o nível de compreensão, o leitor capta as informações oferecidas no texto e as relaciona aos conhecimentos prévios do léxico e do código linguístico que o leitor possui, ou seja, "a capacidade de compreensão em leitura está, portanto, relacionada com a complexidade da estrutura cognitiva do indivíduo. Quem mais tem para contribuir mais possibilidades tem de entender mais coisas" (LEFFA, 1996, p. 29).

Entretanto, é no nível interpretativo de leitura que o conhecimento prévio se une ao conhecimento apresentado no texto, favorecendo a ampliação dos conhecimentos, uma vez que reformula os conceitos e recompõe os esquemas sobre a temática tratada. A etapa interpretativa, embora fortemente ligada à compreensão, tem suas diferenças: a interpretação é idiossincrática, visto que, para se estabelecer, depende dos conhecimentos prévios do leitor; enquanto a compreensão pode ser geral, a interpretação é individualizada; enquanto a compreensão consiste em retirar do texto as respostas adequadas, a interpretação é um ato que exige do leitor a ativação dos seus conhecimentos de mundo, das ligações estabelecidas entre as pistas fornecidas pelo texto e o contexto em que está inserido. Dessa forma, pode-se afirmar que a compreensão é a etapa em que o leitor vai relacionar o conteúdo dado aos conhecimentos prévios para, na etapa da interpretação, construir novos sentidos.

Por sua vez, a etapa da retenção prevê a apreensão e a incorporação dos conhecimentos ampliados no processo, que propiciará a produção de um novo texto, graças às possíveis interpretações.

A leitura que contempla essas quatro etapas implica a leitura crítica, a qual estabelece, a partir de um determinado texto, associações mentais que possibilitam "compreender que em diferentes práticas discursivas os indivíduos criam, recriam e/ou transformam estruturas sociais de dominação, desigualdade e discriminação" (MEURER, 2000, p. 160).

Para a formação de um leitor competente, é necessário considerar o texto e o leitor em um processo interativo em que um possa complementar o outro, construindo novos sentidos ao que é apresentado no texto. 


\section{Texto}

O texto é o lugar de interação de sujeitos sociais, que nele se constituem e são constituídos a partir de pistas textuais fornecidas pelo autor em interação com o conhecimento que o leitor traz para o texto. Ao apresentar a perspectiva interacionista de leitura, Leffa (1996) enfoca o encontro do leitor e do texto e as consequências desse encontro, não mais importando o leitor ou o texto de forma isolada ou a soma das contribuições de cada um, mas os sentidos construídos no processo de interação desenvolvido no momento da leitura. A interação sujeito-linguagem desencadeia o processo criativo no qual a leitura se estabelece.

Ao produzir um texto, o autor ainda não sabe explicitamente quem será seu leitor e seu texto é aberto e cheio de lacunas, as quais o leitor, interlocutor, deverá procurar preencher (DELL'ISOLA, 1996). Entretanto, esse preenchimento não é aleatório, já que, no momento da leitura, o leitor deve buscar, nas pistas deixadas pelo autor, reconstruir o caminho por ele percorrido.

Os Parâmetros Curriculares Nacionais (PCN) de Língua Portuguesa (BRASIL, 1997) apresentam como objetivos para o ensino de língua materna algumas competências que estão relacionadas à atividade de leitura, como: compreender textos orais e escritos; interpretar e inferir as intenções de quem produziu; compreender o sentido nas mensagens orais e escritas das quais é destinatário direto ou indireto e saber atribuir significado segundo os propósitos e as intenções do autor. Esse é um processo no qual o leitor realiza um trabalho ativo de compreensão e de interpretação do texto, a partir de seus objetivos, de seu conhecimento sobre o assunto, sobre o autor, de tudo o que sabe sobre a linguagem, implicando estratégias de seleção, antecipação, inferência e verificação, sem os quais não é possível a proficiência (BRASIL, 1998, p. 69).

Ao ter contato com o texto, o leitor seleciona o que lhe motiva, antecipa definições e informações por meio de hipóteses e infere outras por meio da ligação que integra as informações visuais oferecidas pelo texto e os conhecimentos do leitor (FULGÊNCIO; LIBERATO, 1996). 


\section{Gramática}

A língua se constitui pelo fenômeno social da interação verbal, que se dá por meio de enunciados, plenos de significados, ou seja, textos - espaços em que se encontram os sujeitos com objetivo de interagir por meio da língua. A interação, por sua vez, leva ao desenvolvimento da linguagem proporcionado pela extensão da competência linguística e pela construção ativa de subsistemas gramaticais sobre o sistema já adquirido. Isso já torna claro que não há, hoje, espaço para que se desenvolva, nas salas de aula, um ensino fragmentado, que perca de vista a funcionalidade e a realidade da língua - a interação verbal. Para que essa interação ocorra, primeiramente, aceitamos as variedades linguísticas, o que significa traçar e reconhecer objetivos que visem ao desenvolvimento da capacidade de produção e de interpretação de textos em contextos sócio-históricos verdadeiramente constituídos. Isso implica escolhas adequadas, por parte dos interlocutores, dos recursos expressivos, da variedade linguística e do estilo às diferentes situações comunicativas. Nessa perspectiva, são aos "recursos da língua - em todos os seus planos (fonológico, morfológico, sintático, semântico, pragmático) e níveis (lexical, frasal, textual-discursivo) - em termos de unidades e estruturas (sejam elas fonológicas, morfológicas, sintáticas, textuais)" - que o autor recorre, já que são eles que "funcionam como pistas e instruções de sentidos que são coadjuvados nesta função por mecanismos, fatores e princípios" (TRAVAGLIA, 2004, p. 45).

Assim, concordando com Travaglia, partimos da premissa de que todo falante possui uma gramática internalizada, ou seja, um saber linguístico desenvolvido dentro de certos limites impostos pela sua própria dotação genética humana, sua natureza social e antropológica, mas que também existem regras cuja finalidade é monitorar o funcionamento da língua. Concorrendo com essas considerações, trazemos a perspectiva de que há regras de bom uso da língua, que quebram a espontaneidade do falante, o qual deve ajustar o que pensa às regras pré-determinadas. $\mathrm{O}$ conhecimento dessas regras garantirá ao falante o acesso à norma padrão culto da língua, única forma de uso aceita como correta e gramatical.

Neste trabalho, não descartamos a existência da gramática internalizada, tampouco das gramáticas de usos, normativa e descritiva, já que é possível estudar e compreender a língua sob essas diferentes gramáticas. Primeiramente 
porque a gramática internalizada faz parte de cada falante da língua; compreender isso e aceitar que cada qual traz consigo conhecimentos linguísticos inerentes parece-nos inquestionável. Já a gramática de usos, ou funcional, presta-se à reflexão sobre os usos e o funcionamento da língua nas várias situações comunicativas. Para isso, entra em cena a gramática descritiva, que narra o funcionamento da língua, do conjunto de regras que são usadas pelos falantes. Percebemos que, ao compará-la com a normativa, a gramática descritiva considera gramatical tudo aquilo que possa estabelecer uma comunicação, de acordo com determinada variedade linguística. Auxiliando o processo de reflexão sobre os usos da língua, a gramática normativa surge como um conjunto de regras que se coloca à disposição dos usuários da língua, a serviço da adequação do como se diz aos efeitos de sentido pretendidos, aos objetivos que se quer alcançar com o dizer (falando ou escrevendo) e à situação específica de interação em que estão envolvidos. Isso significa estudar as condições linguísticas da significação, o que contribuirá para o desenvolvimento da competência comunicativa.

A abordagem dessas diferentes - e complementares - gramáticas aponta para percursos que são seguidos do uso à reflexão sobre a língua, cujo processo implica a análise linguística.

\section{Gramática e Análise Linguística}

Quando tomamos como eixos sustentadores do ensino-aprendizagem de Língua Portuguesa o uso e a reflexão, compreendemos a língua no seu percurso natural, isto é, percebemos a competência discursiva, passamos para a textual e chegamos à gramatical. Nesse contexto, a análise linguística (AL) apresenta-se como atividades de reflexão sobre o uso e o sistema linguístico, com o objetivo de tornar a aprendizagem mais significativa, visto que leva à construção progressiva de conhecimentos sobre os fatos da língua.

Não é como sinônimos que intitulamos esta seção com os termos gramática e análise linguística, mas, sim, para enfatizar que a análise linguística não exclui a necessidade e a importância da sistematização, a qual permite ao usuário, principalmente na escola, apropriar-se do sistema e inserir-se nas variadas práticas letradas. Destacamos aqui o Ensino Médio como uma etapa de ensino-aprendizagem em que os alunos devem - e a escola tem a responsabilidade de oferecer condições para - refletir sobre os fenômenos 
linguísticos organizados e contextualmente expostos nas variadas instâncias sociais pelas quais transitam e são produzidos os textos. Isso só é possível se eles chegarem à instrumentalização, que lhe abrirá horizontes para que suas escolhas sejam as mais adequadas às intenções pretendidas na produção textual, e a recursos que lhes permitam ler para além do espaço físico que ocupa o texto. Assim, a AL orienta o usuário da língua, por meio de etapas que vão desde o contato com o material linguístico, passando pela análise do seu entorno, para chegar à sistematização, momento de apropriar-se da metalinguagem.

Dessa forma, gramática e análise não se excluem. Entretanto, uma não é sinônima da outra. Ambas são importantes e auxiliares nos processos de leitura e de produção textual, uma vez que, ao refletir conscientemente sobre os usos linguísticos, o usuário da língua compreenderá a significação dos fenômenos gramaticais e textuais-discursivos pelos quais são atravessados.

Fechando com a concepção de que a gramática envolve uma internalização prévia que se renova por meio da reflexão e da aquisição de novos conhecimentos renovadores, entendemos que deva ser considerada de forma contextualizada.

\section{Ensino e avaliação}

De acordo com Luckesi ([s.d.], p. 1), a “avaliação está relacionada com a ação de buscar um resultado que venha a ser o mais fiel possível à realidade e ao contexto do objeto que se quer avaliar". Ela pode ser de vários tipos: diagnóstica, quando realizada com a finalidade de identificar o que o aluno já conhece, ou classificatória, quando tem como objetivo selecionar candidatos em concurso, vestibular ou qualquer outro teste seletivo.

Neste trabalho, situamos-nos, primeira e especialmente, na avaliação classificatória. Entretanto, não podemos perder de vista a avaliação diagnóstica, já que o processo a que nos propomos analisar se situa, teoricamente, como ponte entre as duas, esperando ser circular. Isso ocorre porque acreditamos e objetivamos que a nota permite ao aluno avaliado e à escola em que se insere interpretarem seu desenvolvimento. Mediante essa avaliação, ambos poderão repensar conteúdos e formas como são ensinados na escola, mesmo que as notas não sejam pontualmente acompanhadas de comentários e propostas dos avaliadores das provas. 
Por isso, o ensino e a avaliação se coordenam nesta seção, esperando que a avaliação, realmente se constitua em instrumento para traçar os caminhos para o ensino-aprendizagem de Língua Portuguesa do Ensino Médio, diretamente ligado ao Ensino Superior, que os alunos esperam alçar quando se inscrevem no Programa de Avaliação Seriada (PAS), uma das formas para ingresso nos cursos de graduação da Universidade Estadual de Maringá (UEM), exclusivamente destinado a alunos regularmente matriculados em escolas de Ensino Médio, públicas ou privadas.

Não existe, porém, avaliação sem instrumentos avaliativos, os quais representam a materialização de mecanismos que captam informações do avaliado. Esses instrumentos podem se concretizar na forma de provas objetivas, de múltipla escolha, dissertativas, trabalhos em duplas, entre outros. Diante da diversidade de tipos de instrumentos de avaliação existentes, a escolha deve pautar-se nos objetivos a que a avaliação se propõe. Para este trabalho, elegemos a Prova de Língua Portuguesa do PAS-UEM, instrumento organizado com questões de múltipla escolha e resultado somatório.

\section{PAS-UEM: o contexto da análise}

Para selecionar os candidatos, as instituições de ensino superior, por meio do vestibular, utilizam a avaliação classificatória com viés marcadamente quantitativo. Esse tipo de avaliação precisa ter objetivos bem definidos, a fim de que realmente seja verificada a aprendizagem e não apenas aptidões de memorização.

O PAS, criado em 25 de junho de 2008, mediante a Resolução no 034/2008-CEP, constitui-se numa das formas para ingresso nos cursos de graduação da UEM. Destina-se exclusivamente a alunos regularmente matriculados em escolas de Ensino Médio, públicas ou privadas, com os seguintes objetivos:

I. ampliar as possibilidades de acesso aos cursos de graduação da UEM;

II. estabelecer uma relação mais intensa entre a Universidade e as escolas de Ensino Médio, permitindo ações que visem a um maior aprimoramento e à interação entre ambas; 
III. selecionar, de forma gradual e sistemática, os alunos-candidatos, valorizando e estimulando um processo contínuo de estudo;

IV. permitir, por meio de informações detalhadas de desempenho do candidato, que tanto os alunos quanto as escolas tenham a oportunidade de monitorar esse desempenho ao longo do Ensino Médio. (Resolução 034/2008-CEP).

As provas escritas são aplicadas no final das séries do Ensino Médio em que o candidato está matriculado, gerando classificação, convocação e processo de matrícula próprios, estando o candidato aprovado sujeito às mesmas normas que os demais participantes do processo vestibular tradicional.

O programa de cada disciplina, referências bibliográficas e demais componentes das provas são definidos por Comitês compostos por: um representante de cada Núcleo de Educação da área de abrangência da região em que se situa a Universidade; dois representantes das escolas conveniadas, indicados pelos Núcleos Regionais, sendo uma das escolas públicas e outro das escolas privadas; e dois docentes da UEM da área e da matéria em questão. Uma banca, nomeada pelo Reitor, elabora as provas, que são anuais e acompanham o calendário do Ensino Médio, acontecendo sempre ao final do ano.

Nas duas primeiras etapas, o candidato realiza a prova sem definir o curso de graduação pretendido, mas, na $3^{\mathrm{a}}$ etapa, no ato da inscrição, deverá indicar a opção pelo curso de graduação, o turno e o campus. Para esses alunos ficam reservadas $20 \%$ das vagas de cada curso. A avaliação realizada num único dia, com a duração de cinco horas - é constituída por três provas, sendo que a terceira, de conhecimentos específicos, só acontecerá na última etapa.

I - prova de Conhecimentos Gerais, com conteúdo de matérias referentes à série correspondente do Ensino Médio;

II - prova de Língua Portuguesa e Literaturas em Língua Portuguesa, Redação e Língua Estrangeira, denominada prova de Línguas, com conteúdo referente à série correspondente do Ensino Médio; III - prova de Conhecimentos Específicos, compondo apenas a prova 
referente à terceira série, que aborda o conteúdo de duas matérias segundo a opção do curso. (Resolução 003/2011-CEP).

Dessas provas, interessa-nos a prova II, da qual trazemos as questões concernentes à Língua Portuguesa, elaborada com questões somatórias de alternativas múltiplas.

A prova tem como objetivo avaliar a capacidade de o candidato:

a) ler e interpretar textos de diferentes níveis de linguagem;

b) perceber as relações estruturais do padrão culto (o sistema ortográfico vigente, as relações morfossintáticas e semânticas entre os fatos da língua);

c) estabelecer relações entre os textos e os contextos a que se referem;

d) reconhecer o emprego de recursos linguísticos utilizados na sua organização. (MANUAL DO CANDIDATO, 2011, p. 46).

Para tanto, a prova contempla questões de leitura e interpretação e questões gramaticais, a partir do(s) texto(s) selecionado(s) (MANUAL DO CANDIDATO, 2011, p. 46). O manual do candidato apresenta os conteúdos específicos de cada etapa, já que o PAS-UEM contempla três, correspondentes gradativamente a cada uma das séries do Ensino Médio: $1^{\mathrm{a}}, 2^{\mathrm{a}}, 3^{\mathrm{a}}$. Interessa-nos a prova elaborada para a Etapa 3, por dois motivos: a) por ser aquela que reúne os conteúdos das três séries do Ensino Médio; b) por ser aquela que seleciona, na soma com as demais etapas, os candidatos mais bem classificados dentro do percentual de vagas ofertadas nos diversos cursos da UEM, destinadas aos concorrentes por esse processo.

Os conteúdos, em princípio, apontam para uma visão estruturalista de ensino, centrado exclusivamente na gramática normativa, já que estabelece um rol de etiquetas gramaticais:

1. Ortografia.

2. Morfossintaxe - período composto;

2.1 Análise sintática;

2.2 Funções das palavras QUE e SE;

2.3 Regência nominal e verbal;

2.4 Colocação de pronomes; 
2.5 Uso do acento grave indicativo de crase;

2.6 Emprego dos sinais de pontuação;

2.7 Função textual dos vocábulos;

2.8 Concordância verbal e nominal;

2.9 Classes de palavras;

2.9.1 Flexão nominal de gênero e de número;

2.9.2 Flexão verbal regular e irregular.

3. Estudo do texto;

3.1 Função textual dos vocábulos;

3.2 Funções de linguagem.

4. Estilística;

4.1 Funções e vícios de linguagem. (MANUAL DO CANDIDATO, 2011, p. 46).

No entanto, considerando os objetivos da prova, apresentados anteriormente, espera-se que as questões propostas não apresentem um foco estruturalista de ensino.

\section{A Prova: análise crítica}

A prova, espaço de interação entre as pesquisadoras e seus elaboradores, é a II, etapa 3, instrumento de avaliação dos candidatos da $3^{\text {a }}$ série do Ensino Médio, participantes das duas etapas anteriores, no ano de 2011, primeiro acesso ao nível superior mediados pelo PAS-UEM.

\section{Apresentação}

A partir do momento em que a avaliação de leitura passa a ser entendida como um instrumento primordial na formação de leitores competentes, conforme lemos nos Parâmetros Curriculares Nacionais - PCN (BRASIL, 1997), torna-se necessária a elaboração de instrumentos de avaliação processuais e formativos que fujam às tradicionais abordagens de avaliação que visam tão somente ao resultado quantitativo.

Na sequência, o texto base para as questões de leitura da prova analisada. As questões serão apresentadas na análise. 


\section{LIINGUA PORTUGUESA}

Texto 1

\author{
Choque entre contextos é da natureza de todas \\ as pilhérias
}

Hélio Schawartsman Articulista da Folha de S.Paulo.

Ok. Eles pegaram pesado. Fazer troça com autistas é quase tão ruim quanto passar rasteira em cego. Mas o simples fato de alguém ter achado que isso seria engraçado

5 já revela um paradoxo: por que somos capazes de rir da desgraça alheia?

Comecemos, no rastro do escritor Arthur Koestler (1905-1983), tentando estabelecer a "gramática" do humor. De um modo geral, 10 rimos quando percebemos um choque entre dois códigos de regras ou de contextos, todos consistentes, mas incompativeis entre si.

Um exemplo: "O masoquista é a pessoa

15 que gosta de um banho frio pelas manhãs e, por isso, toma uma ducha quente". Cometo agora a heresia de explicar a piada. Aqui, o fato de o sujeito da anedota ser um masoquista subverte a lógica normal: ele faz

20 o contrário do que gosta, porque gosta de sofrer. É claro que a lógica normal não coexiste com seu reverso, dai a graça da pilhéria. Uma variante no mesmo padrão, mas com dupla inversão, é: "O sádico é a pessoa que é gentil com o masoquista".

Outro bom exemplo é o do médico que conforta seu paciente dizendo: "Você está com uma doença muito grave. De cada dez pessoas que a pegam, apenas uma

30 sobrevive. E você está com sorte, acabo de perder nove pacientes com essa moléstia".

$\mathrm{O}$ gozado aí emerge da oposição entre a abstração estatística e a concretude do caso real do paciente. Sabemos que a estatística só vale se não a tentarmos aplicar a casos concretos. Também sabemos que as chances de um dado evento ocorrer independem de eventos anteriores. A piada confunde todos esses planos.

Essa estrutura de choque de contextos excludentes entre si está presente em todas as pilhérias. Até no mais infame trocadilho há um confronto inesperado entre o significado da palavra e o seu som: "A ordem dos tratores não altera o viaduto".

Podemos agora traçar uma escala do humor, dos mais primitivos aos mais sofisticados. Bebês, que também são capazes de rir, deliciam-se com caretas e imitações. Garotos pré-adolescentes deliciam-se com piadas escatológicas. Quanto mais cocô, xixi e xingamentos, melhor.

Já adolescentes gostam de anedotas sexuais. À medida que crescem, vão espera-se - buscando formas mais sofisticadas e cerebrais.

Essa "gramática" dá conta da estrutura intelectual das piadas, mas há outros 60 aspectos em jogo. O humor também encerra dinâmicas emocionais. Ele de alguma forma se relaciona com a surpresa.

Kant, na "Crítica do Juízo", diz que o riso é o resultado da "súbita transformação de 65 uma expectativa tensa em nada". Rimos porque nos sentimos aliviados. É nesse contexto que se torna plausível rir de desgraças alheias.

Em alemão, até existe uma palavra para

70 isso: "Schadenfreude", que é o sentimento de alegria ou prazer provocado pelo sofrimento de terceiros. Não necessariamente estamos felizes pelo infortúnio do outro, mas sentimo-nos 75 aliviados com o fato de não termos sido nós a vítima.

Mais ou menos na mesma linha vai o filósofo francês Henri Bergson (1859-1941). Em "O Riso", ele observa que muitas piadas 80 exigem "uma anestesia momentânea do coração". A crueldade é explícita nos chistes mais primitivos (como a "Casa dos Autistas"), mas sobrevive mesmo nos gracejos mais elaborados, na forma de malícia (caso das 85 piadas em que se comparam diversas nacionalidades), autodepreciação (típica do humor judaico) ou, mais simplesmente, na suspensão da solidariedade para com a vítima (sim, piadas geralmente têm vítimas).

90 Há, por fim, a dinâmica social. Bergson vê o riso como um "gesto social". Para o filósofo, o temor de tornar-se objeto de riso reprime as excentricidades do indivíduo. É uma espécie de superego social 95 portátil. É claro que o esquema perde o sentido quando a vítima não tem condições de reagir à provocação humorística, como no caso dos autistas. Mas a ineficácia social não faz com que, no plano da gramática, a

100 piada deixe de ser engraçada. Daí os inevitáveis choques entre humor e adequação social.

(Texto retirado da Folha de S.Paulo, 1. $\% 5 / 2011$. llustrada. E4) 
A prova apresenta cinco questões com cinco alternativas que o candidato deverá analisar e marcar a(s) correta(s). Neste trabalho, optamos por analisar as alternativas que, para serem respondidas, dependem da leitura do texto com os quais os enunciados procuram "conversar", isto é, criam condições para que autor e leitor interajam, a partir do texto. Portanto, as questões 20, 21 e 22, pois as questões 23 e 24 são de análise linguística e dependem não só da capacidade leitora, mas do conhecimento gramatical do avaliado. Tomamos, primeiramente, a questão 20, destacando pontos de interação com o texto para uma análise exemplar:

Questão 20

Assinale a(s) alternativa(s) correta(s) quanto aos aspectos linguísticos presentes no texto 1 .

01) Em "quando a vítima não tem condições de reagir à provocação humorística" (linhas 96-97), o emprego do sinal indicativo de crase é uma exigência da regência da forma verbal "reagir".

02) Em "E você está com sorte, acabo de perder nove pacientes com essa moléstia” (linhas 30-31), a locução verbal destacada em negrito expressa o aspecto verbal cessativo.

04) Em "É nesse contexto que se torna plausível rir de desgraças alheias" (linhas 66-68), a expressão destacada em negrito funciona, no contexto, como sujeito da oração anterior.

08) Em "sentimo-nos aliviados com o fato de não termos sido nós a vítima” (linhas 74-76), a concordância verbal está incorreta, porque a expressão destacada em negrito deveria estar no plural.

16) Em "Aqui, o fato de o sujeito da anedota ser um masoquista" (linhas 17-19), a construção destacada em negrito também poderia ser reescrita da seguinte forma: "o fato do sujeito".

Merecem reflexão dois pontos:

1. O destaque interacional apresenta-se como ancoragem, ou seja, contextualiza a análise linguística (texto 1), cuja etapa de contato com o material linguístico, que na leitura corresponde à decodificação, é motivado pelo 
enunciado inicial da questão: "aspectos linguísticos presentes no texto 1". O candidato é solicitado a ler o texto, a voltar a sua atenção para o material linguístico e entender o porquê das escolhas lexicais e de arranjo textual, para aceitar a sistematização proposta na metalinguagem em que se encerra o enunciado de cada alternativa. Parece não existir a etapa de leitura que exige a análise epilinguística, já que do leitor candidato é solicitada uma resposta voltada para as gramáticas descritiva e normativa: "Em 'quando a vítima não tem condições de reagir à provocação humorística (linhas 96-97), o emprego da crase é uma exigência da regência verbal 'reagir"'. Observa-se o mesmo processo de leitura para cada uma das alternativas apresentadas.

2. Cada enunciado das alternativas interliga-se, não sugerindo a exclusão de uma ou outra delas. Isso converge para o uso e para a reflexão sobre cada enunciado e a sua interação com o texto 1 .

Questão 21

Assinale a(s) alternativa(s) correta(s) quanto ao que se afirma a respeito da sintaxe de colocação pronominal sublinhada.

01) Em "Bebês, que também são capazes de rir, deliciam-se" (texto 1, linhas 48-49), a ênclise é obrigatória por causa da presença da vírgula. 02) Em “o temor de tornar-se objeto de riso" (texto 1, linhas 92-93), pode ocorrer também a próclise devido ao emprego do infinitivo.

04) Em "Rimos porque nos sentimos aliviados" (texto 1, linhas 6566), pode ocorrer ênclise devido ao emprego da conjunção explicativa. 08) Em "De cada dez pessoas que a pegam" (texto 1, linhas 28-29), pode ocorrer ênclise devido ao emprego do gerúndio.

16) Em "a estatística só vale se não a tentarmos aplicar" (texto 1, linhas 34-35), pode ocorrer também ênclise devido à locução verbal.

Observamos que a questão 21 segue percurso similar, não apresentando explicitamente as etapas da leitura. Contudo, implicitamente, para garantir a assinalação das alternativas "corretas", o candidato realiza o movimento entre elas. Ou seja, faz a etapa de decodificação ao identificar a constituição das alternativas e precisa relacionar o seu conhecimento prévio ao que é proposto na alternativa para chegar à resposta correta. 
Questão 22

Assinale a(s) alternativa(s) correta(s) em relação ao conteúdo do texto 1 e ao conteúdo da charge a seguir.

\section{Charge}

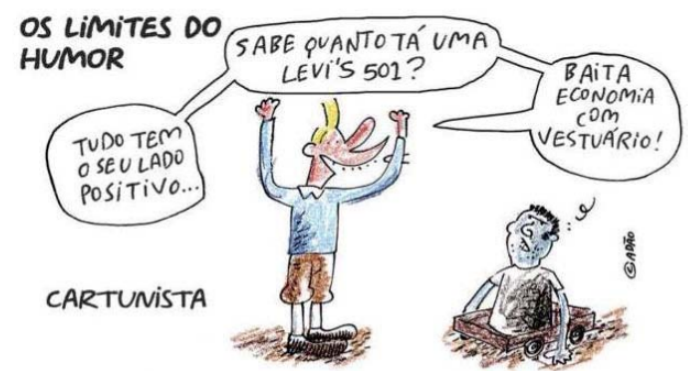

(Adaptado da Folha de S.Paulo, 1.\%/5/2011. E4 ilustrada).

01) Visto que o deficiente da charge não tem condições de reação ao discurso da outra personagem, o humor perde totalmente a sua eficácia, conforme o texto 1 .

02) É possível inferir que, na charge, a personagem em pé sente prazer provocado pelo sofrimento resultante da deficiência física da outra personagem (sentimento denominado "Schadenfreude" em alemão - texto 1, linha 70).

04) O cartunista, por meio da charge, atenua uma desgraça vivida pela personagem deficiente mediante "uma anestesia momentânea do coração" (texto 1, linhas 80-81).

08) O conteúdo da charge evidencia que o seu autor fez sua personagem ter um "gesto social" (texto 1, linha 91) para com a outra personagem que convive com uma deficiência permanente.

16) O autor da charge não segue a "gramática" do humor (texto 1 , linhas 9 e 58), visto que nela não há compatibilidade entre regras e contextos, não há “choques entre humor e adequação social” (texto 1, linhas 101-102). 
A questão 22 apresenta um novo texto, uma charge, que versa sobre o mesmo assunto do texto 1 . O enunciado que encabeça a questão chama o leitor para pôr lado a lado o texto 1 e a charge, texto 2. Para responder, o candidato deverá ler os dois textos, compreender o que é tratado em ambos, procurar similaridades e diferenças no trato do assunto, inferindo em cada um a sua temática - viés pelo qual o autor aborda e recorta o assunto.

A alternativa " 01 ", ao solicitar a aproximação dos dois textos, cria para o leitor condições de ler o entorno de ambos e de perceber, na ativação de conhecimentos prévios, instigada pela figura e pelos elementos que a compõem, o humor ou o deboche descabido do autor do texto 2.

O texto que compõe essa alternativa procura orientar o leitor para a pressuposição de ironia e de deboche que a perpassa. Observamos que os elaboradores - são dois sempre, por exigência da legislação do PAS e um revisor - motivam o candidato a ler a charge na sua totalidade - imagens e texto. Exige-se a leitura nos seus níveis - decodificação, compreensão e interpretação. $\mathrm{O}$ candidato necessita de conhecimentos que lhe permitam aproximar ou não os textos 1 e 2 .

Para assinalar ou não a alternativa " 01 ", o candidato precisa compreender a charge e saber que "LEVIS" é marca de calça jeans e perceber a deficiência física de uma das personagens da charge. Só assim o candidato inferirá que "a baita economia com vestuário" consiste no fato de o interlocutor ser deficiente, não possuir as pernas e, consequentemente, não precisar usar calças compridas. Após isso, precisa fazer uma relação com o primeiro texto, a fim de entender o que é proposto na segunda parte da resposta de número um: "o humor perde totalmente a sua eficácia, conforme o texto 1". Após reler as linhas 95-98 do texto 1, em que se afirma "quando a vítima não tem condições de reagir o esquema perde o sentido", o candidato consegue fechar a sua resposta e reconhecer a primeira alternativa como correta ou não.

A escolha das alternativas aqui discutidas não obedece ao critério de estar apenas entre as corretas, conforme o gabarito disponível no site do PAS, uma vez que não é objetivo deste trabalho discutir o mérito das assertivas. Pontuamos que, em cada alternativa, os elaboradores orientaram-se pela interação e consideraram que gramática não se restringe tão somente à normatização estanque. Inclusive, uma das alternativas nos dá uma pista dessa visão: 
16) $O$ autor da charge não segue a "gramática" do humor (texto 1 , linhas 9 e 58), visto que nela não há compatibilidade entre regras e contextos, não há “choques entre humor e adequação social” (texto 1, linhas 101-102).

Observamos que a leitura não verbal não pode ser desconsiderada, pois as expressões dos rostos podem nos auxiliar sobre a conversa. O garoto loiro está numa posição mais alta e parece gesticular e posicionar-se de forma superior, enquanto que o outro está sentado numa espécie de carrinho de madeira e encontra-se bastante confuso, em um patamar mais baixo e com expressão de dúvida. Todos esses fatores vistos atentamente auxiliarão na percepção da resposta a ser assinalada.

A alternativa " 2 ", por sua vez, enfatiza mais explicitamente a leitura no seu nível compreensivo:

02) É possível inferir que, na charge, a personagem em pé sente prazer provocado pelo sofrimento resultante da deficiência física da outra personagem (sentimento denominado "Schadenfreude" em alemão - texto 1 , linha 70$)$.

Nela é possível inferir, por meio da expressão "Tudo tem seu lado positivo", que uma das personagens, a sem necessidades especiais, busca amenizar a situação do interlocutor fazendo-o enxergar as vantagens de sua situação, pois não precisa adquirir calças tão caras. Para que isso pudesse acontecer, foi necessário à personagem sofrer "uma anestesia momentânea do coração", para deixar de verificar, mesmo por frações de segundos, como o outro poderia se sentir infeliz em não poder usar as pernas. A banalidade a que o personagem loiro se refere, o preço das calças, poderia ser facilmente superada se ele tivesse suas pernas. Essas reflexões, contudo, não precisam ser feitas pelo candidato, pois as informações dadas pela pergunta já estão sugeridas de forma quase explícita no texto 1 ao mencionar o anestesiar do coração e na fala do personagem loiro "tudo tem o seu lado positivo", informação do conhecimento popular que busca sempre agradar ao interlocutor em situações difíceis.

Dessa forma, é possível afirmar que, para responder às questões, o candidato passa pelos dois momentos iniciais do processo de leitura, a 
decodificação e a compreensão, mas não chega à interpretação, pois esta só seria possível se ele pudesse escrever e opinar sobre os aspectos textuais e extratextuais; como isso lhe é negado pela natureza da questão de múltiplas escolhas alternativas, ele precisa limitar-se a simplesmente verificar o que o texto pode oferecer.

As questões 23 e 24, como postulado anteriormente, apresentam questionamentos que dependem muito mais do conhecimento gramatical funcional da língua. Para respondê-las, o candidato pode até precisar retornar ao texto para uma nova leitura, compreendendo-o e interpretando-o, para verificar o funcionamento da língua, ou seja, para realizar uma análise linguística do que é apresentado nas questões.

\section{Considerações Finais}

A prova do PAS-UEM, etapa III, de Língua Portuguesa, como toda prova que avalia por meio de alternativas múltiplas, tem mais um viés de ratificação da leitura que os elaboradores fazem dos textos de apoio do que a leitura livre do candidato. Não podemos, contudo, considerar o processo negativo, já que nele é exigida a leitura em elos: dos textos de apoio, individualmente; dos textos em aproximação; e das leituras a serem ratificadas, quer com a assinalação como correta, quer como a sua desconsideração, por não concordar com ela, das alternativas que não se excluem entre si.

Mesmo como ratificação, o processo avaliativo exige a reflexão a partir do uso e a posição do candidato que mobiliza conhecimentos prévios ampliados pela retenção de outras leituras.

A leitura não contempla as quatro etapas - decodificação, compreensão, interpretação e retenção de forma explícita. Na maioria das vezes, ocorrem a decodificação e a compreensão para definir a resposta correta. No entanto, não dá para dizer que, mesmo de forma internalizada, o leitor não tenha realizado a interpretação para poder escolher marcar ou não a alternativa. Dessa forma, a prova traz a perspectiva da leitura crítica, uma vez que suscita, a partir de textos, associações mentais em que se envolvem diferentes práticas discursivas. Isso confirma, na prova analisada, a concepção interacionista de leitura, sob a qual o leitor e o autor encontram-se no texto e juntos procuram construir sentidos para ele. 
Esse processo interacionista é garantido pela AL, que, ao solicitar do sujeito a reflexão sobre o material linguístico que organiza o texto, leva-o a refletir sobre o seu entorno e estimula a sistematização, significando a apropriação da metalinguagem. Isso se torna óbvio quando os enunciados das alternativas se constroem ancorados no contexto.

A necessidade de relacionar os fatos de dois textos de gêneros diferentes requer um leitor crítico capaz de interpretar o que é proposto na questão e de buscar, nos textos de apoio, solução para as alternativas, mesmo quando o processo avaliativo se organiza com alternativas múltiplas.

É possível verificar que o instrumento de avaliação motiva o candidato a realizar uma leitura dialógica, interativa, levando o leitor a relacionar seus conhecimentos com os dados apresentados no texto e a construir novos conhecimentos.

A gramática é avaliada contextualizadamente, implicando uma análise que parte do uso - os textos de apoio, para a reflexão - para entender por que o autor fez a escolhas linguísticas reveladas, chegando à sistematização e aceitação das normas que regem a língua.

Na prova, objeto de estudo deste trabalho, as habilidades de leitura e de análise linguística se entrelaçam, num diálogo em que autor e leitor se encontram e se reconhecem no texto, confirmando a atenção dos elaboradores aos objetivos do Processo de Avaliação Seriada da Universidade Estadual de Maringá - PAS-UEM.

\section{Referências}

BRASIL. Secretaria de Educação Fundamental. Parâmetros Curriculares Nacionais: língua portuguesa. Brasília: Secretaria de Educação Fundamental, 1997. Disponível em: <http://bit.do/cc2EQ>. Acesso em: 22 fev. 2012.

BRASIL. Secretaria de Educação Fundamental. Parâmetros curriculares nacionais: terceiro e quarto ciclos de ensino de ensino fundamental: língua portuguesa. Brasília: MEC/SEF, 1998. Disponível em: <http://bit.do/cc2E2>. Acesso em: 22 fev. 2012.

BAKHTIN, M. Estética da criação verbal. São Paulo: Martins Fontes, 1997. 
DELL'ISOLA, R. L. P. A interação sujeito-linguagem em Leitura. In: MAGALHÃES, I. (Org.). As múltiplas faces da linguagem. Brasília: UNB, 1996. p. 69-75.

DEMO, P. Mitologias da avaliação: de como ignorar, em vez de enfrentar problemas. 2. ed. Campinas, SP: Autores associados, 2002. (Coleção Polêmicas do nosso tempo; 68).

FULGÊNCIO, L.; LIBERATO, Y. Como facilitar a leitura. 3. ed. São Paulo: Contexto, 1998.

GOULEMOT, J. M. Da leitura como produção de sentidos. In: CHARTIER, R. (Org.). Práticas de leitura. São Paulo: Estação Liberdade, 1996. p. 107-116.

KLEIMAN, A. Oficina de leitura: teoria e prática. Campinas: Pontes; Ed. Unicamp, 1993.

KOCH, I. G. V. Texto: leitura e produção de sentido. Salto para o futuro, Boletim 3, Um mundo de letras: práticas de leitura e escrita, p. 26-39, abr. 2007.

LEFFA, V. J. Aspectos da leitura. Uma perspectiva psicolingüística. Porto Alegre: Sagra; DC Luzzatto, 1996. (Ensaios, 7).

LONARDONI, M. Leitura, gêneros textuais e mídia: notícia \& cia. In: GRECO, E. A.; GUIMARÃES, T. B. (Org.). Leitura, aspectos teóricos e práticos. Maringá: Eduem, 2010.

LUCKESI, C. A base ética da aprendizagem na escola. In: CIPRIANO LUCKESI. Site oficial do Professor Cipriano Carlos Luckesi. Disponível para download em: < http://bit.do/ccTmM>. Acesso em: 13 jan. 2015.

MARTINS, M. H. O que é leitura. São Paulo: Brasiliense, 1994.

MENEGASSI, R. J.; ANGELO, C. M. P. Conceitos de leitura. In: MENEGASSI, R. J. (Org.) Leitura e ensino. Maringá: EDUEM, 2005. p. 15-43. 
MENEGASSI, R. J. Compreensão e interpretação no processo de leitura: noções básicas ao professor. Revista UNIMAR, v. 17, n. 1, p. 85-94, 1995.

MEURER, J. L. O trabalho de leitura crítica: recompondo representações, relações e identidades sociais. Ilha do Desterro, Florianópolis, n. 38, p. 155171, jan./jun. 2000.

PARANÁ. Secretaria de Estado da Educação do Paraná. Departamento de Educação Básica. Diretriz̧es Curriculares da Educação Básica. Curitiba: SEED, 2008. Disponível em: < http://bit.do/cc2Jz>. Acesso em: 25 fev. 2012.

ROMÃO, J. E. Avaliação dialógica desafios e perspectivas. 5. ed. São Paulo: Cortez; Instituto Paulo Freire, 2003.

SOLÉ GALLART, I. Estratégias de leitura. Tradução Cláudia Schilling. 6. ed. Porto Alegre: ArtMed, 1998.

TRAVAGLIA, L. C. Gramática: ensino plural. 2. ed. São Paulo: Cortez, 2004. 